TOFANELLI, M.B.D.; AMAYA-ROBLES, J.E.; RODRIGUES, J.D.; ONO, E.O. Ácido giberélico na produção de frutos partenocárpicos de pimenta. Horticultura Brasileira, Brasília, v. 21, n. 1, p. 116-118, março 2003.

\title{
Ácido giberélico na produção de frutos partenocárpicos de pimenta
}

\author{
Mauro Brasil Dias Tofanelli ${ }^{1}$; Julio Estuardo Amaya-Robles ${ }^{1}$; João Domingos Rodrigues²; Elizabeth \\ Orika Ono ${ }^{2}$ \\ ${ }^{1}$ UNESP, FCA, C. Postal 237, 18.603-970 Botucatu-SP; ${ }^{2}$ UNESP, IBB, C. Postal 510, 18.618-000 Botucatu-SP. E-mail: maurobdt@ bol.com.br
}

\begin{abstract}
RESUMO
A presença de sementes em frutos, dependendo da espécie, pode ser dispensável ou até mesmo indesejável ao consumo e à culinária, como seria o caso, por exemplo, de algumas pimentas. Este trabalho teve como objetivo avaliar o efeito da aplicação de ácido giberélico $\left(\mathrm{GA}_{3}\right)$ na produção e nas características de frutos partenocárpicos em plantas de pimenta "escabeche" (Capsicum baccatum L.). A semeadura foi realizada em bandejas de poliestireno expandido e o plantio das mudas em estrutura plástica com irrigação por gotejamento. O delineamento experimental foi em blocos casualizados com quatro tratamentos $\left(0 ; 700 ; 1.400\right.$ e $2.800 \mathrm{mg} \mathrm{L}^{-1}$ de $\mathrm{GA}_{3}$ ). Foram feitas duas aplicações de $\mathrm{GA}_{3}$ : a primeira quando as plantas estavam em plena floração e a segunda aos 10 dias após a primeira aplicação. Observou-se que o $\mathrm{GA}_{3}$ favoreceu a produção de frutos partenocárpicos $\left(94,6 \%\right.$ com $2.100 \mathrm{mg} \mathrm{L}^{-1}$ de $\left.\mathrm{GA}_{3}\right)$, diminuiu a produção de frutos $\left(87,1 \mathrm{~g}\right.$ fruto/planta com $2.250 \mathrm{mg} \mathrm{L}^{-1} \mathrm{de}$ $\left.\mathrm{GA}_{3}\right)$, aumentou a altura da planta $\left(168,0 \mathrm{~cm}\right.$ com $2.450 \mathrm{mg} \mathrm{L}^{-1} \mathrm{de}$ $\mathrm{GA}_{3}$ ), porém, prejudicou as características comerciais dos frutos. É possível produzir frutos partenocárpicos com a aplicação de $\mathrm{GA}_{3}$ em pimenta "escabeche", porém esta técnica não foi agronomicamente viável.
\end{abstract}

Palavras chave: Capsicum baccatum L., Solanaceae, apirenia, regulador vegetal.

\begin{abstract}
Gibberellic acid on pepper parthenocarpic fruits production

The presence of seeds in fruits can be dispensable or undesirable for consumption and cooking, as for example, in some peppers. The effect of gibberellic acid $\left(\mathrm{GA}_{3}\right)$ on parthenocarpic fruit production and fruit traits in "escabeche" pepper was evaluated (Capsicum baccatum L.). Seeds were sown in polystyrene trays and seedlings were grown in greenhouses. The experimental design was a randomized complete block, with four treatments $(0 ; 700 ; 1,400$ and $2,800 \mathrm{mg} \mathrm{L}^{-1} \mathrm{GA}_{3}$ ). $\mathrm{GA}_{3}$ was sprayed at flowering stage and 10 days after the first application. The results showed that $\mathrm{GA}_{3}$ increased the percentage of parthenorcapic fruits (94.6\% with $\left.2,100 \mathrm{mg} \mathrm{L}^{-1} \mathrm{GA}_{3}\right)$, decreased fruit production $\left(87,1 \mathrm{~g}\right.$ fruit/plant with $\left.2,250 \mathrm{mg} \mathrm{L}^{-1} \mathrm{GA}_{3}\right)$. increased plant height $\left(168.0 \mathrm{~cm}\right.$ with $\left.2,450 \mathrm{mg} \mathrm{L}^{-1} \mathrm{GA}_{3}\right)$, and reduced the fruit quality. It is possible to produce parthenocarpic fruits through $\mathrm{GA}_{3}$ application on "escabeche" pepper, however this technique is not recommended for commercial production.
\end{abstract}

Keywords: Capsicum baccatum, Solanaceae, seedless, plant growth substance.

(Recebido para publicação em 22 de fevereiro de 2002 e aceito em 20 de dezembro de 2002)

$\mathrm{A}$ s pimentas e pimentões (gênero Capsicum) são de grande importância agrícola, utilizados como constituintes de saladas e temperos. Países latinoamericanos, como Peru e México, são reconhecidos pela utilização destes frutos em sua culinária tradicional.

As pimentas são representadas por várias espécies do gênero Capsicum, destacando-se a $C$. baccatum que possui diferentes variedades botânicas, como por exemplo, a variedade pendulum de ocorrência no noroeste da América do Sul e no sudoeste do Brasil (Oliveira et al., 2000), também conhecida popularmente como "escabeche" ou "Aji amarillo" ou "Aji escabeche" em outros países como o Peru.

Frutos sem sementes (apirenia) têm melhor qualidade comercial, uma vez que a presença de sementes dificulta seu aproveitamento e manuseio, como é o caso das pimentas para preparo de tem- peros, salsas e pastas (Shifriss \& Eidelman, 1986). A apirenia é utilizada com sucesso em uva (Vitis vinifera) e citros (Citrus spp.). Entretanto, para o gênero Capsicum e para as pimentas, praticamente, não existem relatos na literatura científica. Alguns reguladores vegetais podem ser utilizados para estimular a partenocarpia, tais como giberelinas, auxinas e citocininas. A giberelina quando aplicada exógenamente nas plantas, promove a partenocarpia (Cano-Medrano \& Darnell,1997), sendo o $\mathrm{GA}_{3} \mathrm{o}$ mais utilizado por produzir frutos bem similares àqueles produzidos em condições normais (Rodrigo \& GarcíaMartínez, 1998).

Dos poucos trabalhos científicos existentes na literatura, destaca-se o desenvolvido por Kohli et al. (1981) que avaliaram a aplicação de 0,$625 ; 1.250$; 2.500; 5.000 e $10.000 \mathrm{mg} \mathrm{L}^{-1}$ de $\mathrm{GA}_{3}$ em plantas de pimentão (C. annuиm L.) e obtiveram $0 ; 55,3 ; 66,7 ; 71,4 ; 76,2$ e $87,5 \%$ de partenocarpia nas respectivas concentrações de $\mathrm{GA}_{3}$.

Neste trabalho objetivou-se produzir frutos partenocárpicos em pimenta "escabeche" através da aplicação exógena de diferentes concentrações de ácido giberélico, bem como avaliar sua influência na altura das plantas e nas características comerciais dos frutos.

\section{MATERIAL E MÉTODOS}

$\mathrm{O}$ trabalho foi desenvolvido na Faculdade de Ciências Agronômicas da UNESP, de outubro/00 a março/01.

As sementes da pimenta "escabeche" (Capsicum baccatum var. pendulum) foram semeadas em bandejas de poliestireno expandido (128 células) com substrato comercial (Plantimax), sendo colocadas em casa de sombreamento $50 \%$ (telado) para 
germinarem, onde permaneceram por 45 dias até o transplantio no interior de uma estrutura plástica, no espaçamento de $0,8 \times 1,0 \mathrm{~m}$. Realizou-se adubação de plantio aplicando $10 \mathrm{~g}$ de $\mathrm{N}, 10 \mathrm{~g}$ de $\mathrm{P}_{2} \mathrm{O}_{5}$ e $10 \mathrm{~g}$ de $\mathrm{K}_{2} \mathrm{O}$ por metro linear de sulco e, em cobertura aplicou-se $10 \mathrm{~g}$ de $\mathrm{N}$ e $10 \mathrm{~g}$ de $\mathrm{K}_{2} \mathrm{O}$ por metro linear de plantio. As linhas de plantio foram irrigadas por gotejamento. O tutoramento das plantas foi feito com auxílio de barbante fixado a arames lisos suportados por moirões de madeira a $1,8 \mathrm{~m}$ do solo. Quando necessário, foram realizadas pulverizações mensais com o inseticida Parathion Metil (Folisuper) e com o fungicida Mancozeb (Dithane) e capinas manuais para o controle das plantas daninhas na área experimental.

O delineamento experimental foi de blocos casualizados com quatro tratamentos $\left(0 ; 700 ; 1.400\right.$ e $2.800 \mathrm{mg} \mathrm{L}^{-1} \mathrm{de}$ $\mathrm{GA}_{3}$ ), cinco repetições e quatro plantas por repetição. Considerou-se apenas as duas plantas centrais para a coleta de dados, totalizando dez plantas por tratamento.

Para o preparo da solução de $\mathrm{GA}_{3}$, diluiu-se o produto na forma de pó em água destilada. A aplicação do $\mathrm{GA}_{3}$ foi realizada com pulverizador costal, em duas épocas (a primeira quando as plantas se encontravam em plena floração e a segunda 10 dias após a primeira) (Kohli et al., 1981).

Os frutos foram colhidos em março 2001. Avaliou-se a porcentagem de frutos partenocárpicos, massa total de frutos por planta, altura da planta e características relacionadas aos frutos (massa média dos frutos, diâmetro médio dos frutos, comprimento médio dos frutos e porcentagem de frutos deformados).

Realizou-se análise de variância (teste F) para avaliação da significância do fator e regressão polinomial para avaliar o efeito das concentrações de $\mathrm{GA}_{3}$ em cada parâmetro avaliado, ambos a 5\% de probabilidade (Gomes, 1990).

\section{RESULTADOS E DISCUSSÃO}

$\mathrm{O} \mathrm{GA}_{3}$ promoveu altos índices de frutos partenocárpicos de pimenta, obtendo-se tendência de um máximo de 94,6\% de partenocarpia na concentração de $2.100 \mathrm{mg} \mathrm{L}^{-1}$ de $\mathrm{GA}_{3}$ (Figura 1).

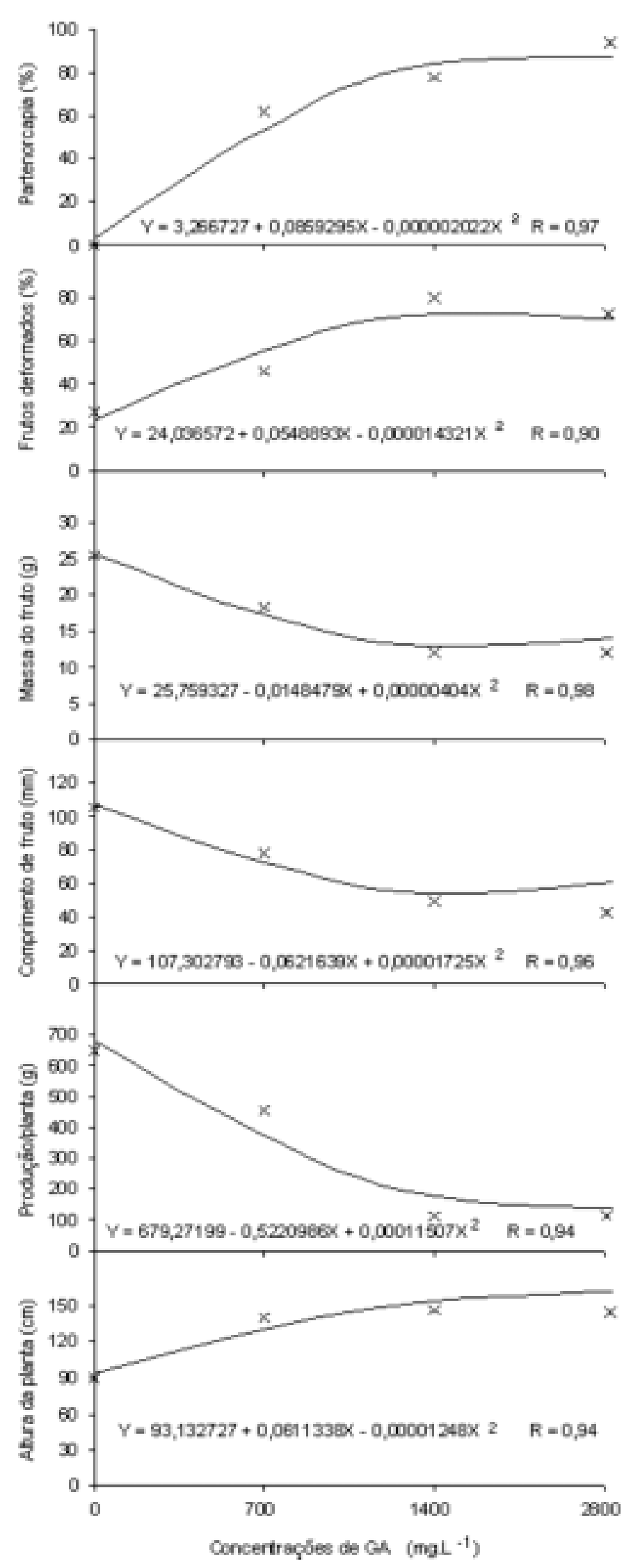

Figura 1. Efeito do ácido giberélico $\left(\mathrm{GA}_{3}\right)$ na produção de frutos partenocárpicos e deformados, na produção de frutos por planta, na massa e comprimento do fruto e no crescimento de planta em pimenta "escabeche". 
A aplicação exógena de giberelinas pode reduzir a viabilidade do pólen e a fertilidade dos óvulos (Thomas, 1995), estimulando a produção de frutos sem polinização. Kohli et al. (1981) obtiveram maior porcentual de frutos sem sementes de pimentão com $\mathrm{GA}_{3}$ em alta concentração $\left(10.000 \mathrm{mg} \mathrm{L}^{-1}\right)$, por atuar como androcida, pois estimulou a esterilidade masculina.

O fornecimento crescente das concentrações de $\mathrm{GA}_{3}$ diminuiu a produção de frutos, tendendo a um mínimo de 87,1 $\mathrm{g}$ de frutos por planta com $2.250 \mathrm{mg} \mathrm{L}^{-1}$ de $\mathrm{GA}_{3}$ (Figura 1). Esta queda na produção de frutos pode ser atribuída ao alto índice de aborto dos botões florais e ao excessivo crescimento vegetativo das plantas ocasionado pelas concentrações de $\mathrm{GA}_{3}$ utilizadas. Segundo Metzger (1995), a aplicação de $\mathrm{GA}_{3}$ em plantas pode provocar juvenilidade, aborto e queda de flores.

A aplicação do regulador vegetal favoreceu o crescimento vegetativo das plantas, observando-se tendência de altura máxima de $168,0 \mathrm{~cm}$ com $2.450 \mathrm{mg}$ $\mathrm{L}^{-1}$ de $\mathrm{GA}_{3}$ (Figura 1). Isto demonstra que o $\mathrm{GA}_{3}$ pode ter induzido a divisão celular e/ou o alongamento das células. De acordo com Davies (1995), uns dos principais efeitos das giberelinas é estimular o hiper-alongamento de ramos através do aumento da divisão e alongamento celular.

$\mathrm{O} \mathrm{GA}_{3}$ desfavoreceu a produção de frutos de qualidade, ou seja, diminuiu a massa do fruto, tendendo a um mínimo de 12,1 g com $1.850 \mathrm{mg} \mathrm{L}^{-1}$ de $\mathrm{GA}_{3}$; o comprimento dos frutos, tendendo a um mínimo de 51,3 mm com $1.800 \mathrm{mg} \mathrm{L}^{-1}$ de $\mathrm{GA}_{3}$ e aumentou o porcentual de frutos deformados, tendendo a um máximo de 76,6\% com $1.900 \mathrm{mg} \mathrm{L}^{-1}$ de $\mathrm{GA}_{3}$
(Figura1). Na variável diâmetro de fruto não houve efeito significativo do $\mathrm{GA}_{3}$. Uma das causas deste aumento do porcentual de frutos defeituosos pode ser o aumento da porcentagem de frutos partenorcárpicos causado pela aplicação do $\mathrm{GA}_{3}$ e, conseqüentemente, pelo desbalanço hormonal ocorrido nos frutos, principalmente pela possível diminuição exógena de auxina. Para Taiz \& Zeiger (1991), o desenvolvimento normal do fruto é dependente da auxina produzida no desenvolvimento das sementes.

O comprometimento da qualidade de frutos pela aplicação exógena de giberelina também foi relatado em vários trabalhos, como os de Iwahori et al. (1968) em uva, de Devilin \& Demoranville (1967) em arandos (Vaccinium macrocarpon Ait.), de Stembrigde \& Gambrell (1972) em pêssego e o de García-Martínez \& GarcíaPapí (1979) em citros (Citrus reticulata Blanco) todos citados por CanoMedrano \& Darnell (1997).

Conclui-se que o ácido giberélico influenciou positivamente na produção de frutos partenocárpicos de pimenta "escabeche" e favoreceu o crescimento das plantas. Em contrapartida, diminuiu a produção de frutos por planta e a qualidade comercial dos mesmos. Diante dos resultados obtidos e nas condições em que o experimento foi conduzido, não recomenda-se a aplicação de $\mathrm{GA}_{3}$ para a produção de frutos partenocárpicos de pimenta "escabeche". Entretanto, novos estudos baseados no presente trabalho, poderiam fornecer informações complementares da técnica de aplicação de $\mathrm{GA}_{3}$ objetivando-se induzir a partenocarpia em pimenta "escabeche" e obter características comerciais satisfatória do produto agrícola.

\section{LITERATURA CITADA}

CANO-MEDRANO, R.; DARNELL, R.L. Cell number and cell size in parthenocarpic vs. Pollinated blueberry (Vaccinium ashei) fruits. Annals of Botany, v. 80, p. 419-425, 1997.

DAVIES, P.J. The plant hormones: their nature, occurrence, and functions. In: DAVIES, P.J. Plant hormones: physiology, biochemistry and molecular biology. (2Ed). Amsterdam: Kluwer Academic Publishers, 1995. p. 1-12.

GOMES, F.P. Curso de estatística experimental. (13Ed). Esalq, Piracicaba, 1990. 467 p.

KOHLI, U.K.; DUA, L.S.; SAINI, S.S. Gibberellic acid as na androecide for bell pepper. Scientia Horticulturae, v. 15, n. 1, p. 17-22, 1981. METZGER, J.D. Hormones and reproductive development. In: DAVIES, P.J. Plant hormones: physiology, biochemistry and molecular biology. (2Ed). Amsterdam: Kluwer Academic Publishers, 1995. p. 617-648.

OLIVEIRA, A.B.; SILVA, A.M.; LOPES, C.A.; RIBEIRO, C.S.C.; LOPES, D.; CRUZ, D.M.R.; MARQUES, D.M.C.; FRANÇA, F.H.; REIFSCHNEIDER, F.J.B.; BUSO, G.S.C.; BIANCHETTI, L.B.; FERREIRA, M.E., POZZOBON, M.T.; RESENDE, R.O.; CARVALHO, S.I.C.; PINHEIRO, V.L.; CASALI, V.W.D.; Capsicum: pimentas e pimentões no Brasil. EMBRAPA: CNPH, Brasília, 2000. 113 p.

RODRIGO, M.J.; GARCÍA-MARTÍNEZ, J.L. Hormonal control of parthenorcarpic ovary growth by the apical shoot in pea. Plant Physiology, v. 116, p. 511-518, 1998.

SHIFRISS, C.; EIDELMAN, E. An approach to parthenocarpy in peppers. HortScience, v. 21, n. 6, p. 1458-1459, 1986.

TAIZ, L., ZEIGER, E. Auxins: growth and tropisms. In:_. Plant Physiology, California: The Benjamin/Cummings Publishing Company, 1991. p. 398-425.

THOMAS, G. Natural and synthesis growth regulators and their use in horticultural and agronomic crops. In: DAVIES, P.J. Plant hormones: physiology, biochemistry and molecular biology. (2Ed). Amsterdam: Kluwer Academic Publishers, 1995. p. 751-773. 